\title{
A Draft Genome Assembly of "Cas" (Psidium Friedrichsthalianum (0. Berg) Nied): An Indigenous Crop of Costa Rica Untapped.
}

Mónica Rojas-Gómez ( $\square$ morogo27@gmail.com )

Centro Nacional de Innovaciones Biotecnológicas (CENIBiot) https://orcid.org/0000-0002-0245-2911 Jose Pablo Jiménez-Madrigal

Instituto Tecnológico de Costa Rica

Maripaz Montero-Vargas

Advanced Computing Laboratory (CNCA), CeNAT-CONARE,1174-1200 San José

Randall Loaiza-Montoya

Centro Nacional de Innovaciones Biotecnológicas (CENIBiot)

\section{Max Chavarría}

Centro Nacional de Innovaciones Biotecnológicas (CENIBiot)

\section{Esteban Meneses}

Advanced Computing Laboratory (CNCA), CeNAT-CONARE,1174-1200 San José

Eric J. Fuchs

Universidad de Costa Rica

\section{Short Report}

Keywords: P. friedrichsthalianum, Cas, indigenous crop, draft genome assembly, genomic resources, functional food.

Posted Date: July 14th, 2021

DOl: https://doi.org/10.21203/rs.3.rs-707890/v1

License: (c) (1) This work is licensed under a Creative Commons Attribution 4.0 International License. Read Full License

Version of Record: A version of this preprint was published at Genetic Resources and Crop Evolution on November 16th, 2021. See the published version at https://doi.org/10.1007/s10722-021-01291-5. 


\section{Abstract}

Psidium friedrichsthalianum (0. Berg) Nied is a tropical tree species in the Myrtaceae family, natively distributed from southern Mexico, to eastern Venezuela and Ecuador and commonly known as "Cas", "Costa Rican guava" or "Sour Guava". The "Cas" produces a fruit with a rather distinctive acidic flavor and has bioactive compounds and biological potential equal or greater than common Guava; is considered an indigenous crop in Costa Rica with characteristics as a functional food untapped. This species has not been completely domesticated, and can be found in home gardens, paddocks, small groups, and, more recently, in small and medium sized plantations. Also, the plantations of this species do not have technical and scientific support or agronomic promotion from industry, nor are there genetic resources or germplasm readily available to farmers. This limits its commercial development and the implementation of selection or genetic improvement programs. In this study, we present the first draft assembly of the Cas genome using PacBio long reads and the Canu assembly pipeline. Our draft assembly has a total length of $417.64 \mathrm{Mb}$, with 24440 contigs and a N50 contig size of $21.3 \mathrm{~Kb}$. Structural annotation resulted in 59036 gene models. Functional annotation was conducted against the non-redundant set of genes from the KEGG database. Of the 52422 complete genes models, $15.55 \%$ (8 153) presented homology with KEGG orthologs. The genes found in our Cas draft assembly were compared to those found in Eucalyptus grandis (rose gum) [erg] in the KEGG repository. According to the KEGG pathway assignments, 33 isoforms were annotated as part of the flavonoid biosynthetic pathway. In addition, 19 isoforms were annotated as part of phenylpropanoid biosynthetic pathway. The results of this study provide an overview of the first draft of the Cas genome assembly using PacBio long reads. This new genomic resource represents the basis for exploring the genetic potential of this crop with characteristics as a functional food.

\section{Introduction}

Psidium friedrichsthalianum (0. Berg) Nied is a tropical tree species in the Myrtaceae family, subfamily Myrtoideae, tribe Myrteae (Lucas et al. 2019). This family includes several plant species of economic importance, such as guava (Psidium guajava), eucalyptus (Eucalyptus grandis), wax apple (Syzygium samarangense), and pink myrtle (Rhodomyrtus tomentosa) (Grattapaglia et al. 2012; Wilson et al. 2004). $P$. friedrichsthalianum is a medium-sized tree (Fig. 1), natively distributed from southern Mexico, to eastern Venezuela and Ecuador (Govaerts et al. 2008). This tree has perfect allogamous flowers (Barahona and Rivera 1995) and produces a fleshy berry-like fruit, commonly known as "Cas", "Costa Rican guava" or "Sour Guava" (Cuadrado-Silva et al. 2017a). The fruit has a greenish to yellow exocarp and a pulp with a rather distinctive acidic flavor (Cuadrado-Silva et al. 2017a, 2017b; Thaptimthong et al. 2016). This species is diploid $(2 n=2 x=22)$ (Srivastava 1977), with a genome size of $958 \mathrm{Mb}$ (RojasGómez et al. 2020).

Recent studies have shown that fruit of Cas ( $P$. friedrichsthalianum) has bioactive compounds and biological potential equal or greater than guava ( $P$. guajava) (González et al. 2012; Cuadrado-Silva et al. 2017a). This tree produces phenolic compounds, mainly quercetin aglycones and proanthocyanidins, 
derived from epi-catechin units. Other compounds such as ellagitannins and benzophenones have also been putatively identified (Rojas-Garbanzo et al. 2021; Rojas-Garbanzo et al. 2019; Cuadrado-Silva et al. 2017a, 2017b; Granados-Chinchilla et al. 2016; Flores et al. 2013; González et al. 2012). Previous studies have categorized it as a functional food due to its association with positive health effects. Anti-diabetic, anti-plasmodic, hepatoprotective, antioxidant, antimicrobial, anti-inflammatory, and anti-platelet activity are some of the reported bioactivities for leaves and fruit extracts (Cuadrado-Silva et al. 2017b, González et al. 2012; Flores et al. 2015; Flores et al. 2013; Granados-Chinchilla et al. 2016; Rojas-Garbanzo et al. 2021).

In Costa Rica, the fruit of Cas is consumed mainly as fresh fruit and is used to prepare traditional foods, such as pasteurized soft drinks, ice creams, juices, desserts, and jams. It is sold at grocery stores and farmers markets (León 2000). In Costa Rica, this species has not been completely domesticated, and can be found in home gardens, paddocks, small groups, and, more recently, in small and medium-sized plantations. In general, Cas is considered an indigenous crop in Costa Rica with characteristics as a functional food untapped. The plantations of this species do not have technical and scientific support or agronomic promotion from industry, nor are there genetic resources or germplasm readily available to farmers. This limits its commercial development and the implementation of selection or genetic improvement programs.

Previous work on the assembly of the complete genome of economically important members of the Myrtaceae, such as Psidium guajava (Feng et al. 2020), Eucalyptus grandis (Myburg et al. 2014) and Leptospermum scoparium (Mānuka) (Thrimawithana et al. 2019) has been published. In this study, we present the first draft assembly of the Cas genome (P. friedrichsthalianum) using PACBio long reads and the Canu assembly pipeline (Koren et al. 2017). This new genomic resource represents the basis for exploring the genetic potential of this crop with characteristics as a functional food.

\section{Materials And Methods}

\section{Sampling permits}

All the needed permits for sampling leaf tissue from Cas were requested by Comisión de BiodiversidadUCR at Universidad de Costa Rica (under permit \# 133-2018) and Mr. Alfonso Ruíz, owner of the farm where the sampling was carried out.

\section{Plant material, DNA preparation, and genome sequencing}

Plant material used for this study was collected from a small plantation located at Tacacori, Alajuela, Costa Rica (DMS: $10^{\circ} 03^{\prime} 07.3^{\prime \prime} \mathrm{N}-84^{\circ} 12^{\prime} 52.3^{\prime \prime} \mathrm{W}$ ). Leaf tissue was collected from mature trees and transported to the laboratory at room temperature in sterile polypropylene tubes $(50 \mathrm{~mL})$ containing silica gel. Genomic DNA was extracted from 4 samples of $50 \mathrm{mg}$ each of dry leaf tissue, using the DNeasy Plant Mini kit (QIAGEN, Inc.). DNA size, quantity, and integrity was assessed with an Agilent's TapeStation system (model 4200, CA, USA). The sample with the highest molecular weight and DNA integrity was 
selected for sequencing. SMRTbell library preparation (template size 4-10 Kb) and next-generation sequencing was performed by the North Carolina State University Genomic Sciences Laboratory (Raleigh, NC, USA) using the PacBio Sequel I system.

\section{Genome assembly, gene prediction, and annotation}

Raw reads (BAM files) from each SMRTcell were converted to FASTQ format, using bam2fastq, and collated into a single file. These long reads were corrected, trimmed and assembled using Canu v2.0 (Koren et al. 2017), with corrected Error Rate set to 0.155 , min Read Length set to 500, min Overlap Length set to 400, and genome size equal to $958 \mathrm{Mbp}$, based on previous flow cytometry estimates (RojasGómez et al. 2020). Genome assembly quality statistics were estimated with QUAST v5.0.2 (Gurevich et al. 2013) and assembly completeness was assessed with BUSCO v4.1.2, using the Eudicotyledons (odb10) database (Seppey et al. 2019). Structural annotation and gene predictions were obtained with Augustus v3.3.3 (Stanke et al. 2008) and filtered with gFACs v1.1.2 (Caballero and Wegrzyn 2019), excluding incomplete gene models and redundant exons.

Functional annotation was performed with BlastKOALA (Kanehisa et al. 2016) and the non-redundant set of genes from the KEGG database (Kanehisa and Goto 2000; Kanehisa 2019; Kanehisa et al. 2021), using default parameters. Additionally, annotation of the flavonoid biosynthesis pathway was performed using modules M00137 and M00138, from genes annotated in Eucalyptus grandis (rose gum) [egr], a member of the Myrtaceae family and the closest relative for which there is data available.

\section{Results And Discussion}

\section{Genome assembly and annotation}

A de novo draft assembly of the Cas genome was produced using $58.7 \mathrm{~Gb}$ of PacBio Sequel I raw data and the Canu assembler pipeline. The draft assembly has a total length of $417.64 \mathrm{Mb}$, with 24440 contigs and a N50 contig size of $21.3 \mathrm{~Kb}$. The assembly length accounts for only $43.6 \%$ of the expected genome size and yet it presents $62.6 \%$ complete universal single-copy orthologs (Table 1 ). This may indicate the accumulation of repetitive DNA or transposable elements (TE) throughout the evolutionary history of the species (Rojas-Gomez et al. 2020), which contributes to the larger genome size but are hard to sequence and assemble. Partial or complete genome duplication is also a common feature in plant genomes (Wendel et al. 2016). The GC content of the Cas draft assembly was $40.05 \%$, similar to that of $P$. guajava (Feng et al. 2020) and E. grandis (Myburg et al. 2014), the two most closely related species with sequenced genomes.

Structural annotation of the draft assembly resulted in 59036 gene models. However, after filtering out incomplete genes, overlapping exons, and duplicates, a total of 52422 genes were retained. This is a larger number of predicted protein-coding genes than in the sequenced genomes of the myrtaceous species, L. scoparium (Mānuka) (31 220 genes), E. grandis (36 376 genes) and P. guajava (25 601 genes) (Thrimawithana et al. 2019; Myburg et al. 2014; Feng et al. 2020). In addition, of the remaining gene 
models, 6106 correspond to mono-exonic genes, while 46316 correspond to multi-exonic genes. On average, multi-exonic genes are composed of 5.9 exons and 4.9 introns. Median CDS length was 1279 nt, but multi-exonic gene size varies greatly with CDS ranging from 209 nt to 14373 nt. For mono-exonic genes the average length was $948.6 \mathrm{nt}$. This is consistent with reports of plants having more protein coding genes of smaller size and with fewer exons per gene than other organisms (Ramirez-Sanchez et al. 2016).

Functional annotation was conducted against the non-redundant set of genes from the KEGG database. Of the 52422 complete genes models, 15.55\% (8 153) presented homology with KEGG orthologs. The majority of the annotated genes correspond with genetic information processing pathways, such as proteins involved in transcription and translation processes, as well as folding, sorting and degradation. The second largest group of annotated genes (\%) correspond to environmental information processing pathways, including membrane transport and signal transduction. Finally, the third largest group of annotated genes correspond to carbohydrate metabolism pathways. A complete distribution of the functional categories of the annotated genes is presented in Fig. 2. The remaining gene models, that is the ones without annotation, were classified as hypothetical proteins. Many of these gene models showed homology with other hypothetical proteins reported in the NCBI database from both closely and distantly related species (data not shown). Because there is not reported evidence of their function in vivo these hypothetical proteins remain uncharacterized.

\section{Genes involved in flavonoid biosynthesis}

The most important flavonoids in Cas are proanthocyanidins, anthocyanins, and flavonols (quercetin aglycones). All three classes are being intensively investigated for their potential benefit to human health and are the compounds that provide functional food properties. For example, proanthocyanidins are thought to help in maintaining urinary tract health (Howell 2002; Foo et al. 2000), anthocyanins are important as antioxidants (Yan et al. 2002; Sun et al. 2002), and flavonols are implicated in antiplasmodic, hepatoprotective, anti-inflammatory, and anti-cancer bioactivities, among others (Hollman and Katan 1997; Ren et al. 2003). Thus, considering the importance of the flavonoids, in this study we focus on analyzing the presence of genes involved in its biosynthesis. For this, we obtained the KEGG reference pathway for flavonoid biosynthesis (KEGG modules: M00137 and M00138; KEGG map: map00941, Fig. 3) and phenylpropanoid biosynthesis (KEGG map: map00940, Fig. 4). Then, we compared our Cas draft assembly with annotated genes of Eucalyptus grandis (rose gum) [erg] in the KEGG repository. According to the KEGG pathway assignments, 17 isoforms were annotated for chalcone synthase (K00660; [EC:

2.3.1.74]), 4 isoforms were annotated for trans-cinnamate 4-monooxygenase (K00487; [EC: 1.14.1491]), 3 isoforms for chalcone isomerase (K01859; [EC: 5.5.1.6]), 6 for naringenin 3-dioxygenase (K00475; [EC:1.14.11.9]), 1 for anthocyanidin synthase (K05277; [EC:1.14.20.4]) and 2 isoforms for flavanone 4reductase (K13082; [EC:1.1.1.219 1.1.1.234]); these genes are part of the flavonoid biosynthetic pathway (Fig. 3). In addition, 10 isoforms were annotated for phenylalanine ammonia lyase (K10775; [EC:

4.3.1.24]) and 9 isoforms for 4-coumarate-CoA ligase (K01904; [EC: 6.2.1.12]); as part of the phenylpropanoid biosynthetic pathway (Fig. 4 and Table S1). 
The genes and regulatory mechanisms involved in the flavonoid pathway are of great interest in Cas, as these affect the temporal and spatial flavonoid biosynthesis as well as the specific flavonoids produced. It has been shown that the central pathway for flavonoid biosynthesis is conserved in most plants, but depending on the species, a group of enzymes, such as isomerases, reductases, hydroxylases and several $\mathrm{Fe}^{2+} / 2$-oxoglutarate-dependent dioxygenases can modify their basic flavonoid skeleton, generating different subclasses of flavonoids (Martens et al. 2010). Likewise, it has been shown that flavonoid biosynthesis is tissue specific, regulated by development and can be induced by a variety of environmental factors, including light, UV radiation, fungal infection, interaction with microorganisms, wounding, among others (Winkel-Shirley 2001). This study presents the first annotation of genes involved in flavonoid biosynthesis for Cas. These genes can be targeted for manipulation of flavonoid biosynthesis through various means or used as markers for the selection of desirable flavonoid profiles through breeding. For example, in cranberry it has been shown that an important aspect of anthocyanins as antioxidants is the specific aglycone, as well as the glucoside, since this affects both the antioxidant potential and the bioavailability (Satué-Gracia et al. 1997; Wang et al. 1997).

The results of this study provide as a genetic resource an overview of the first draft of the Cas genome assembly using long PacBio reads. This assembly represents the basis for new genomic and molecular studies in the future of this crop. In particular, it delves into the evolution of secondary metabolites, mainly of the polyphenolic type, which give this crop special characteristics as a functional food.

\section{Declarations}

\section{Acknowledgments}

We thank local Cas farmer, Mr. Alfonso Ruíz, who provided free samples from his farm.

\section{Author contributions}

M. Rojas-Gómez: Conceptualization, methodology, investigation, formal analysis, writing - original draft, project administration. JP. Jiménez-Madrigal: Methodology, formal analysis, writing - review \& editing, data curation. M. Montero-Vargas: Methodology, formal analysis, data curation, writing - review \& editing. R. Loaiza-Montoya: Review \& editing, funding acquisition, project administration. M. Chavarría: Review \& editing, supervision. E. Meneses: Review \& editing, supervision, funding acquisition. E.

Fuchs: Conceptualization, investigation, writing - review \& editing.

\section{Funding Information}

This work was supported by the Centro Nacional de Alta Tecnología (CeNAT-CONARE), Foundation of Costa Rica (3-006-213777).

\section{Data availability statements}


The whole-genome sequence of Cas has been deposited at the DDBJ/ENA/GenBank databases under BioProject PRJNA725514, under the accession JAGVVM000000000. The version described in this paper is version JAGVVM010000000. Available data includes raw reads, draft assembly sequence, and gene models. https://www.ncbi.nlm.nih.gov/search/all/?term=PRJNA725514

\section{Competing Interest}

The authors declared that they have no conflict of interest in this work.

\section{References}

1. Baraona M, Rivera G (1995) Development of jocote (Spondias purpurea L.) and cas (Psidium friedrichsthalianum Niedz) in the premontano humid forest of Costa Rica. Mesoamerican Agronomy. 6: 23-31.

2. Broun $P$ (2005) Transcriptional control of flavonoid biosynthesis: a complex network of conserved regulators involved in multiple aspects of differentiation in Arabidopsis. Curr. Opin. Plant Biol. 8: 272-279. https://doi.org/10.1016/j.pbi.2005.03.006.

3. Caballero M, Wegrzyn J (2019) gFACs: Gene Filtering, Analysis, and Conversion to Unify Genome Annotations Across Alignment and Gene Prediction Frameworks. Genomics, Proteomics \& Bioinformatics. 17(3): 305-310. https://doi.org/10.1016/j.gpb.2019.04.002.

4. Cuadrado-Silva CT, Pozo-Bayón MÁ, Osorio C (2017a) Identification of aroma compounds and precursors of sour guava (Psidium friedrichsthalianum Nied.) following a sensomics approach. Eur Food Res Technol. 243: 1-10. https://doi.org/10.1007/s00217-016-2716-y.

5. Cuadrado-Silva CT, Pozo-Bayón MÁ, Osorio C (2017b) Targeted Metabolomic Analysis of Polyphenols with Antioxidant Activity in Sour Guava (Psidium friedrichsthalianum Ndz.). Fruit Molecules.22 (1): 11. https://doi.org/10.3390/molecules22010011.

6. Feng C, Feng C, Lin X, Liu S, Li YKang M (2020) A chromosome-level genome assembly provides insights into ascorbic acid accumulation and fruit softening in guava (Psidium guajava). Plant Biotechnol J. https://doi.org/10.1111/pbi.13498.

7. Flores G, Dastmalchi K, Wu SB, Whalen K, Dabo AJ, Reynertson K (2013) Phenol-rich extract of the Costa Rican guava pulp (Psidium friedrichsthalianum $\mathrm{Ndz}$ ) with antioxidant and anti-inflammatory activity. Potential for COPD therapy. Food Chemistry. 14: 889895. https://doi.org/10.1016/j.foodchem.2013.03.025.

8. Flores G, Wu SB, Negrin A, Kennelly EJ (2015) Chemical composition and antioxidant activity of seven cultivars of guava (Psidium guajava) fruits. Food Chemistry. 170:327335. https://doi.org/10.1016/j.foodchem.2014.08.076.

9. Foo L, Lu Y, Howell AB, Vorsa N (2000) A-Type proanthocyanidin trimers from cranberry that inhibit adherence of uropathogenic P-fimbriated Escherichia coli. J Nat Prod Chem. 63 (9): 12251228. https://doi.org/10.1021/np000128u. 
10. González E, Vaillant F, Pérez AG, Rojas T (2012) Antioxidant protection mediated by in vitro cells of human erythrocytes by some common tropical fruits. J Nutr Food Sci. 2: 139. https://doi.org/10.4172/2155-9600.1000139.

11. Govaerts R, Sobral N, Ashton P, Barrie F, Holst BK, Landrum LL, Matsumoto K, Fernanda Mazine F, Nic Lughadha, Proença C (2008) World Checklist of Myrtaceae: Kew Publishing, Royal Botanic Gardens. 1-455.

12. Granados-Chinchilla F, Villegas E, Molina A, Arias C (2016) Composition, Chemical Fingerprinting and Antimicrobial Assessment of Costa Rican Cultivated Guavas (Psidium friedrichsthalianum (O. Berg) $\mathrm{Ndz}$ and Psidium guajava L.) Essential Oils from Leaves and Fruits. Nat Prod Chem Res. 4:5. https://doi.org/10.4172/2329-6836.1000236.

13. Grattapaglia D, Vaillancourt RE, Shepherd M, Thumma BR, Foley W, Külheim C, Potts B.M (2012) Progress in Myrtaceae genetics and genomics: Eucalyptus as the pivotal genus. Tree Genet. Genomes. 8: 463- 508. https://doi.org/10.1007/s11295-012-0491-x.

14. Gurevich A, Saveliev V, Vyahhi N, Tesler G (2013) QUAST: quality assessment tool for genome assemblies. Bioinformatics. 29 (8): 1072-1075. https://doi.org/10.1093/bioinformatics/btt086.

15. Hollman PCH, Katan MB (1997) Absorption, metabolism and health effects of dietary flavonoids in man. Biomed Pharmacother. 51: 305-310. https://doi.org/10.1016/S0753-3322(97)88045-6.

16. Howell $A B$ (2002) Cranberry proanthocyanidins and the maintenance of urinary tract health. Crit Rev Food Sci Nutr. 42: S3: 273-278. https://doi.org/10.1080/10408390209351915.

17. Humann JL, Lee T, Ficklin S, Main D (2019) "Structural and Functional Annotation of Eukaryotic Genomes with GenSAS." Gene Prediction: Methods and Protocols. Ed. Martin Kollmar. New York: Humana Press. 29-51. https://doi.org/10.1007/978-1-4939-9173-0_3.

18. Kanehisa M, Furumichi M, Sato Y, Ishiguro-Watanabe M, Tanabe M (2021) KEGG: integrating viruses and cellular organisms. Nucleic Acids Research. 49(1): 545-551. https://doi.org/10.1093/nar/gkaa970.

19. Kanehisa M, Goto S (2000) KEGG: kyoto encyclopedia of genes and genomes. Nucleic acids Research. 28(1): 27-30. https://doi.org/10.1093/nar/28.1.27.

20. Kanehisa M, Sato Y, Morishima K (2016) BlastKOALA and GhostKOALA: KEGG tools for functional characterization of genome and metagenome sequences. J. Mol. Biol. 428: 726-731. https://doi.org/10.1016/j.jmb.2015.11.006.

21. Kanehisa M (2019) Toward understanding the origin and evolution of cellular organisms. Protein Science. 28(11): 1947-1951. https://doi.org/10.1002/pro.371.

22. Koren S, Walenz BP, Berlin K, Miller JR, Bergman NH, Phillippy AM (2017) Canu: scalable and accurate long-read assembly via adaptive k-mer weighting and repeat separation. Genome Research. 27(5): 722-736. https://doi.org/10.1101/gr.215087.116.

23. León J.2000. Botany of tropical crops. San José, Costa Rica: Ed. Ilca. pp. 445.

24. Lucas EJ, Holst B, Sobral M, Mazine FF, Barnes-Proença CE, Ribeiro da Costa I, Vasconcelos TNC (2019) A New Subtribal Classification of Tribe Myrteae (Myrtaceae). Systematic Botany. 44(3): 560- 
569. https://doi.org/10.1600/036364419X15620113920608.

25. Martens S, Preuss A, Matern U (2010) Multifunctional flavonoid dioxygenases: flavonols and anthocyanin biosynthesis in Arabidopsis thaliana L. Phytochemistry 71:10401049. https://doi.org/10.1016/j.phytochem.2010.04.016.

26. Myburg A, Grattapaglia D, Tuskan G (2014) El genoma de Eucalyptus grandis. Nature 510: 356362. https://doi.org/10.1038/nature13308.

27. Pollastri S, Tattini M (2011) Flavonols: old compounds for old roles. Ann.Bot. 108:12251233. https://doi.org/10.1093/aob/mcr234.

28. Ramırez-Sanchez O, Perez-Rodrıguez P, Delaye L, Tiessen A. (2016). Plant Proteins Are Smaller Because They Are Encoded by Fewer Exons than Animal Proteins. Genomics Proteomics Bioinformatics. 14: 357-370. https://doi.org/10.1016/j.gpb.2016.06.003.

29. Ren W, Qiao Z, Wang H, Zhu L, Zhang L (2003) Flavonoids: Promising anticancer agents. Med Res Rev. 23: 519-534. https://doi.org/10.1002/med.10033.

30. Rojas-Garbanzo C, Rodríguez L, Pérez AM, Mayorga-Gross AL, Vásquez-Chaves V, Fuentes E, Palomo I (2021) Anti-platelet activity and chemical characterization by UPLC-DAD-ESI-QTOF-MS of the main polyphenols in extracts from Psidium leaves and fruits. Food Research International.

141(1):45. https://doi.org/10.1016/j.foodres.2020.110070.

31. Rojas-Garbanzo C, Wintera J, Montero ML, Zimmermanna BF, Schiebera A. (2019) Characterization of phytochemicals in Costa Rican guava (Psidium friedrichsthalianum Ndz) Fruit and stability of main compounds during juice processing - (U) HPLC-DAD- ESI-TQD-MS. Journal of Food Composition and Analysis. 75: 26-42. https://doi.org/10.1016/j.foodres.2020.110070.

32. Rojas-Gómez M, García-Piñeres A, Bolaños-Villegas P, Arrieta-Espinoza G, Fuchs EJ (2020) Genome size and chromosome number of Psidium friedrichsthalianum (O. Berg) Nied ("Cas") in six populations of Costa Rica. Caryologia. International Journal of Cytology, Cytosystematics and Cytogenetics 73(3):55-63. https://doi.org/10.13128/caryologia-646.

33. Rojas-Rodríguez F, Torres-Córdoba G (2013) Trees of the Central Valley of Costa Rica: reproduction Cas (Psidium friedrichthalianum (Berg) Ndz). Kurú Mesoamerican Forest Magazine (Costa Rica). 120 (10): 1320-1323. https://hdl.handle.net/2238/5373.

34. Satué-Gracia MT, Heinonen M, Frankel EN (1997) Anthocyanins as antioxidants on human lowdensity lipoprotein and lecithin-liposome systems. J Agric Food Chem. 45 (9): 33623367. https://doi.org/10.1021/jf970234a.

35. Seppey M, Manni M, Zdobnov E.M (2019) BUSCO: Assessing Genome Assembly and Annotation Completeness. In: Kollmar M. (eds) Gene Prediction. Methods in Molecular Biology, vol 1962. Humana, New York, NY. https://doi.org/10.1007/978-1-4939-9173-0_14.

36. Srivastava HC. 1977. Cytological studies in Psidium friedrichsthalianum Niedenzu. Cytologia. 42: 395-400. https://doi.org/10.1508/cytologia.42.395.

37. Stanke M, Diekhans M, Baertsch R, Haussler D (2008) Using native and syntenically mapped cDNA alignments to improve de novo gene finding. Bioinformatics. 24(5): 637- 
644. https://doi.org/10.1093/bioinformatics/btn013.

38. Sun J, Chu YF, Wu X, Liu RH (2002) Antioxidant and antiproliferative activities of common fruits. J Agric Food Chem. 50 (25): 7449-7454. https://doi.org/10.1021/jf0207530.

39. Thaptimthong T, Kasemsuk T, Sibmooh N, Unchern S (2016). Platelet inhibitory effects of juices from Pachyrhizus erosus L. root and Psidium guajava L. fruit: A randomized controlled trial in healthy volunteers. BMC Complementary and Alternative Medicine.16 (1):

269. https://doi.org/10.1186/s12906-016-1255-1.

40. Thrimawithana AH, Jones D, Hilario E, Grierson E, Liachko I, Sullivan S, et al. (2019). A whole genome assembly of Leptospermum scoparium (Myrtaceae) for Mānuka research. New Zealand Journal of Crop and Horticultural Science. https://doi.org/10.1080/01140671.2019.1657911.

41. Wang H, Cao G, Prior RL (1997) Oxygen radical absorbing capacity of anthocyanins. J Agric Food Chem. 45: 304-309. https://doi.org/10.1021/jf960421t.

42. Wendel J, Jackson S, Blake C (2016) Meyers, and Rod A. Wing. Evolution of plant genome architecture. Genome Biology. 17:37. https://doi.org/10.1186/s13059-016-0908-1.

43. Wilson PG, O'Brien M, Heslewood MM, Quinn C (2004) Relationships within Myrtaceae sensu lato based on a matK phylogeny. Plant Syst. Evol. 251, 3- 19. https://doi.org/10.1007/s00606-004-0162y.

44. Winkel-Shirley B (2001) Flavonoid biosynthesis. A colorful model for genetics, biochemistry, cell biology, and biotechnology. Plant Physiol. 126: 485-493. https://doi.org/10.1104/pp.126.2.485.

45. Winkel-Shirley B (2006) "The biosynthesis of flavonoids," in The Science of Flavonoids. ed E. Grotewold (New York, NY: Springer). 71-95.

46. Yan X, Murphy BT, Hammond GB, Vinson JA, Neto CC (2002) Antioxidant activities and antitumor screening of extracts from cranberry fruit (Vaccinium macrocarpon). J Agric Food Chem. 50: 58445849. https://doi.org/10.1021/jf0202234.

\section{Tables}

Table 1. Summary statistics of Cas ( $P$. friedrichsthalianum) draft genome.

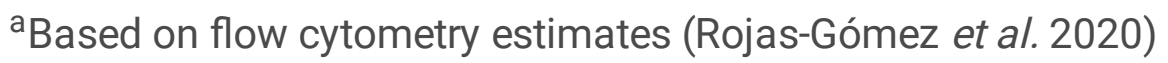

\section{Figures}




\begin{tabular}{|ll|}
\hline Estimated genome size $(\mathrm{n}, \mathrm{Mb})^{\mathrm{a}}$ & 958 \\
\hline Assembly size $(\mathrm{Mb})$ & 417.64 \\
\hline Number of contigs & 24440 \\
\hline Largest contig (bp) & 182085 \\
\hline N50 (bp) & 21274 \\
\hline L50 (bp) & 6131 \\
\hline GC (\%) & 40.05 \\
\hline Number of N's per $100 \mathrm{Kbp}$ & 0.0 \\
\hline BUSCOs & C: $62.5 \%$ [S:57.4\%, D:5.1\%], F:10.9\%, M:26.6\%, n:2121 \\
\hline
\end{tabular}
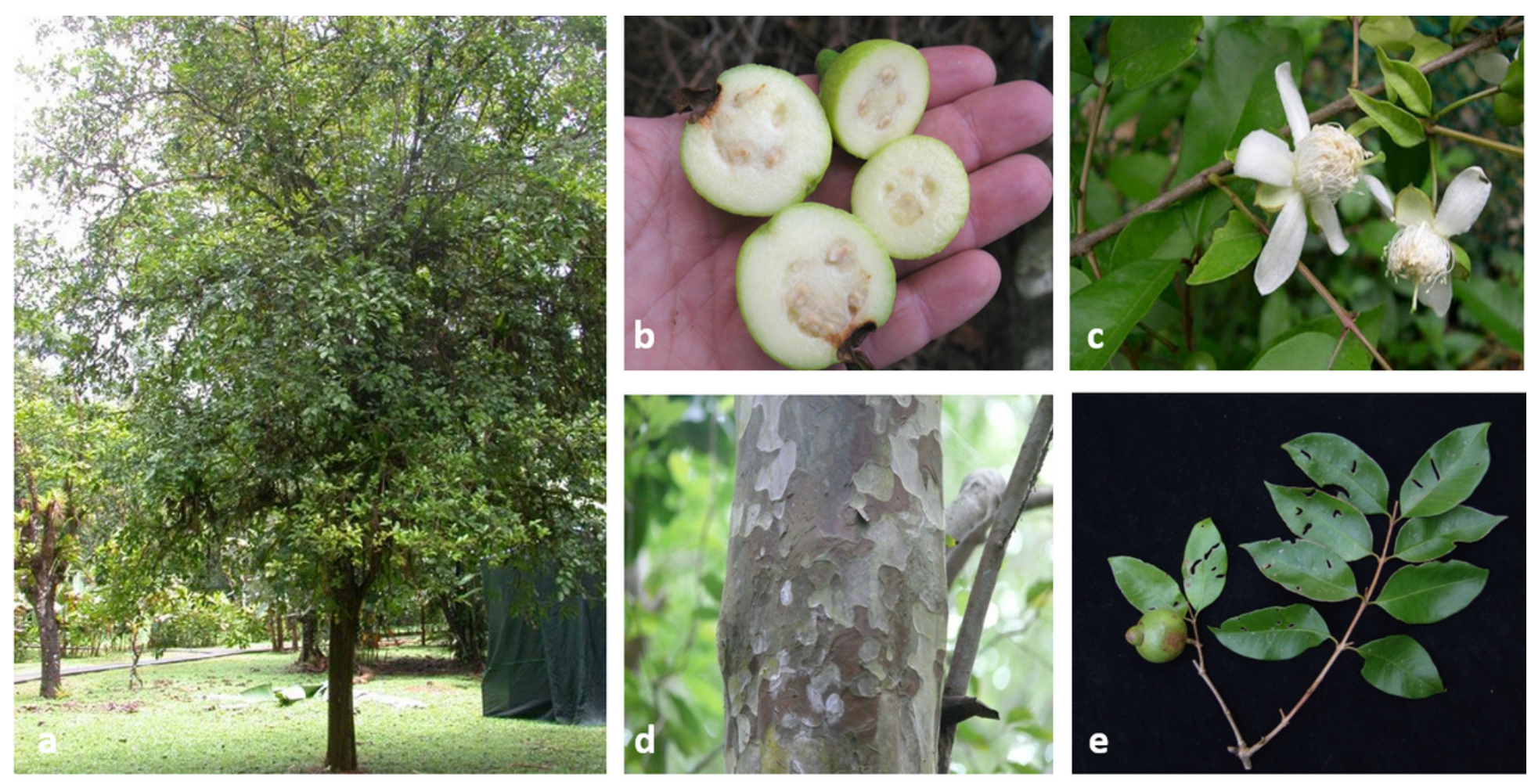

Figure 1

(a) Image of a Cas tree (P. friedrichsthalianum) located in Tacacorí, Alajuela, Costa Rica (DMS: $10^{\circ} 03$ '07.3"N - 84 $12^{\prime} 52.3^{\prime \prime} \mathrm{W}$ ) (b) Cas fruits (c) Cas tree flowers hermaphrodites (d) Cas tree trunk (e) Cas tree branch, characterized by being reddish and having foliage of intense green color. 


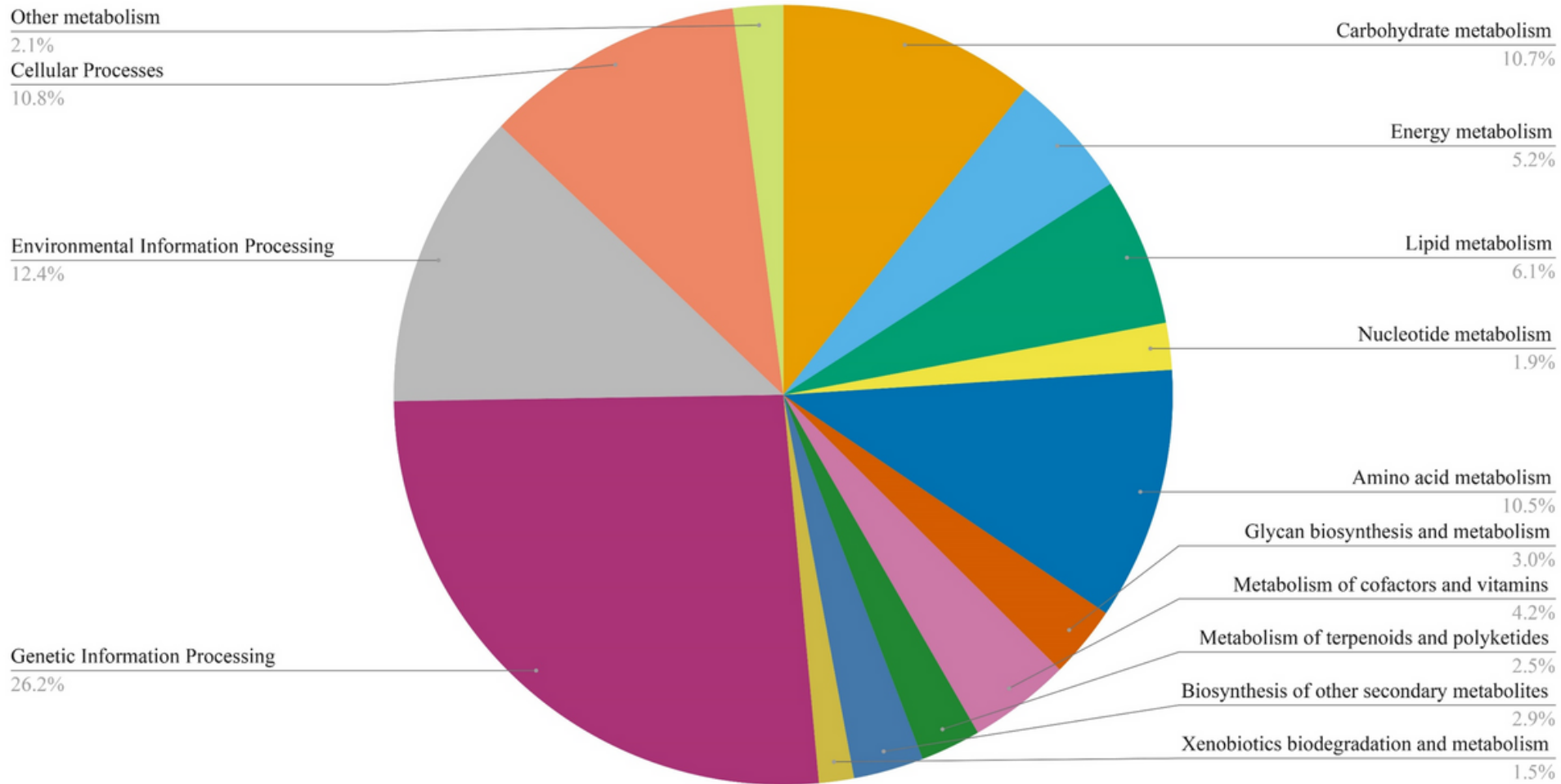

\section{Figure 2}

Percentage of $\mathrm{KO}$ terms per functional category in Cas annotated genes. Annotated genes are grouped together into major functional categories, based on the non-redundant set of genes and pathways from the KEGG database. 


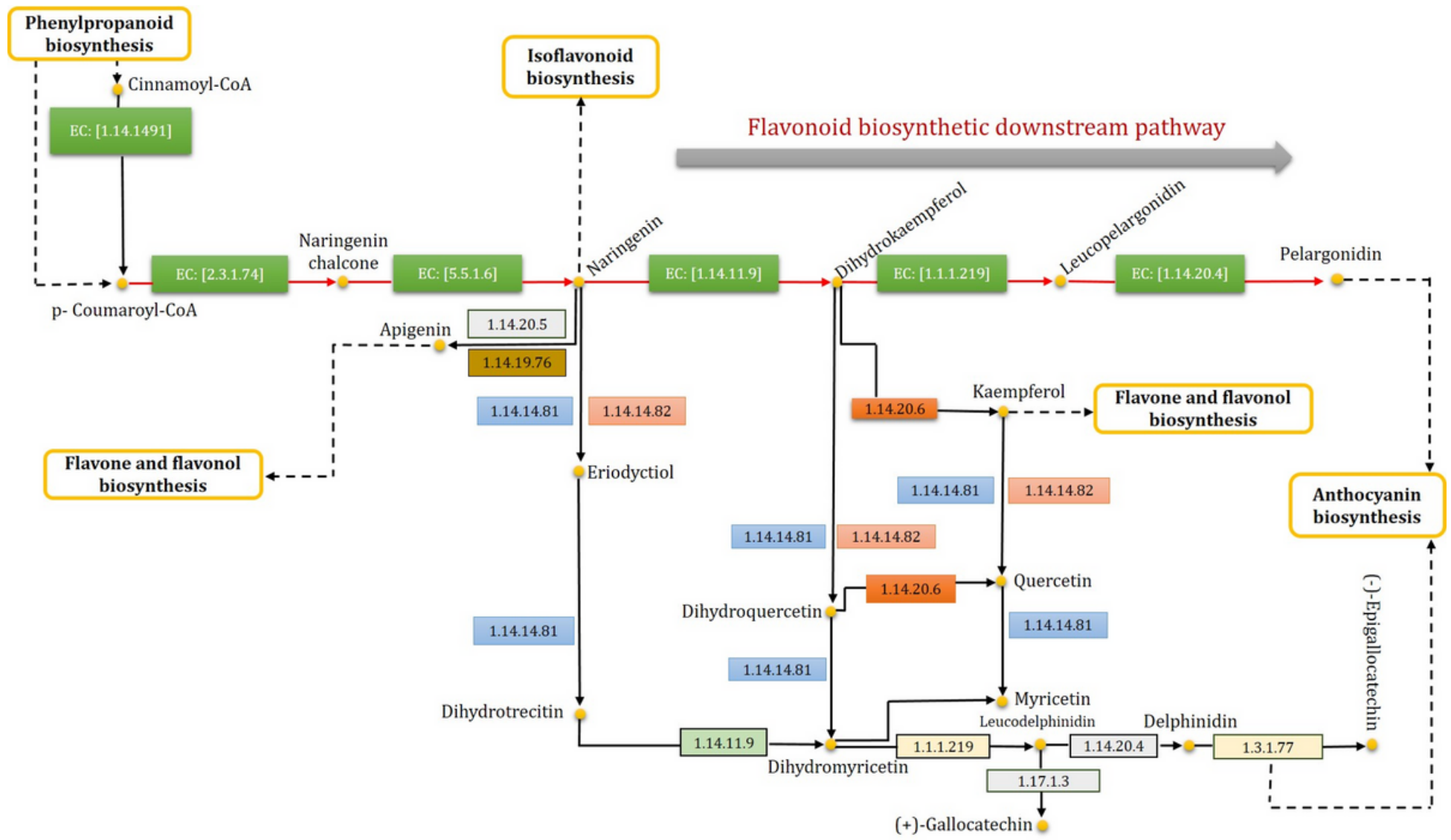

\section{Figure 3}

KEGG reference pathway for flavonoid biosynthesis (map00941): Red lines correspond to flavonoid biosynthetic upstream and downstream pathway. Green boxes correspond to functional annotation of genes for Cas (EC:1.14.1491: trans-cinnamate 4-monoxygenase; EC: 2.3.1.74: chalcone synthase; EC: 5.5.1.6: chalcone isomerase; EC: 1.14.11.9: naringenin 3-dioxygenase; EC: 1.1.1.219: bifunctional dihydroflavol 4-reductase; EC: 1.14.20.4: anthocyanidin synthase). 
Phenylpropanoid biosynthesis

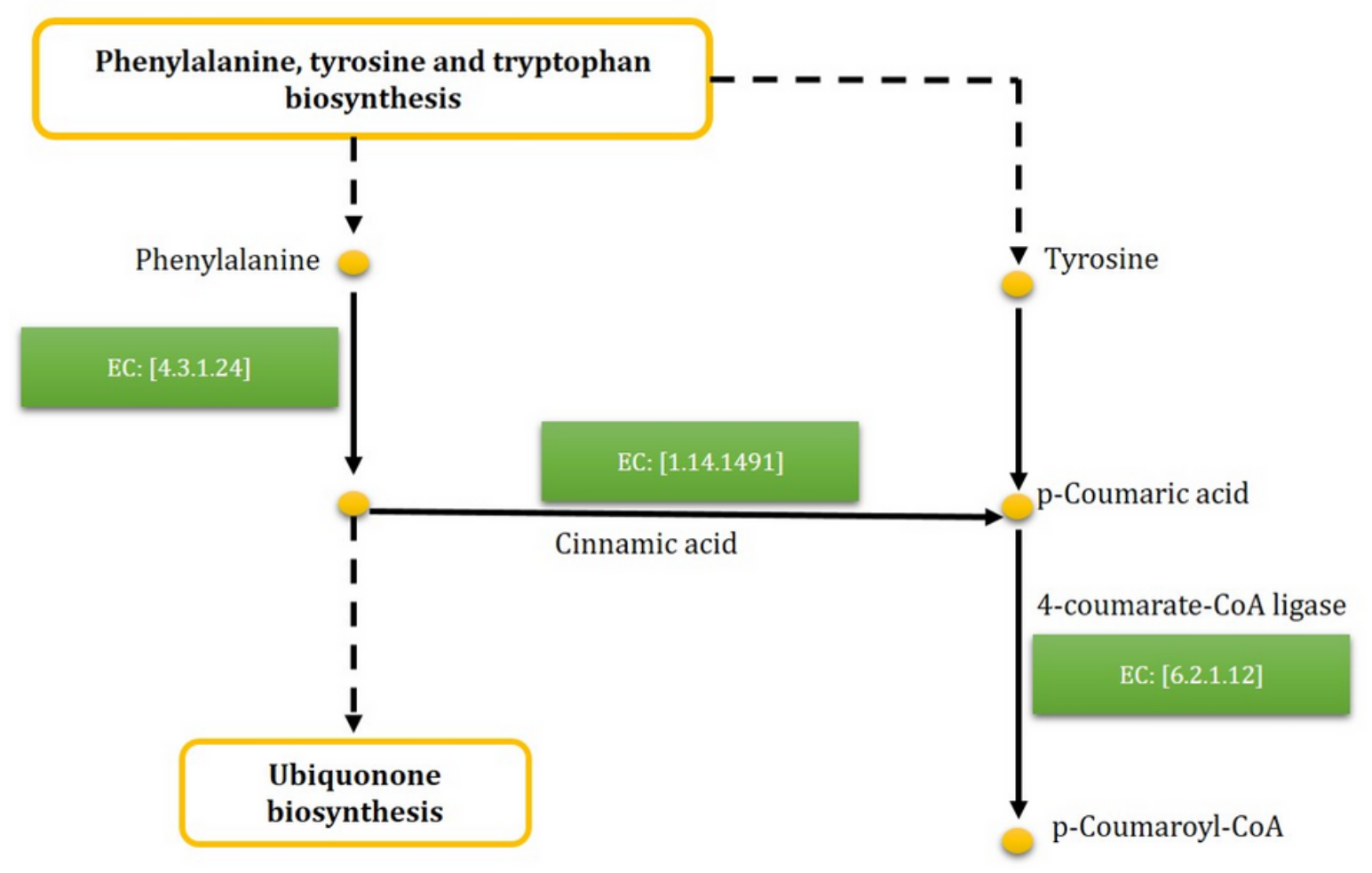

\section{Figure 4}

KEGG reference pathway for phenylpropanoid biosynthesis (map 00940): Green boxes correspond to functional annotation of genes for Cas related to flavanone biosynthesis as part of the phenylpropanoid biosynthetic pathway (EC: 4.3.1.24: phenylalanine ammonialyase; EC: 1.14.1491: trans - cinnamate 4 monoxygenase; EC: 6.2.1.12: 4-coumarate-CoA ligase).

\section{Supplementary Files}

This is a list of supplementary files associated with this preprint. Click to download.

- SupplementarymaterialTableS1.docx 